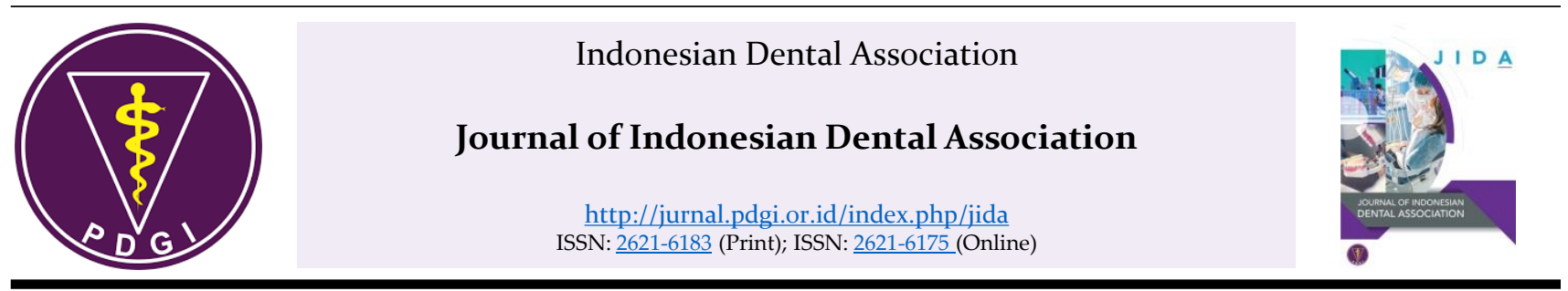

Research Article

\title{
Differences in Taste Sensitivity between Vegans and Non-Vegetarians in Palembang, Indonesia
}

\author{
Takami Abbilardo ${ }^{1}$, Shanty Chairani ${ }^{2 \S}$, Nursiah Nasution ${ }^{3}$ \\ ${ }^{1}$ Undergraduate Student, Dentistry Study Program, Faculty of Medicine, Sriwijaya University, Indonesia \\ ${ }^{2}$ Dentistry Study Program, Faculty of Medicine, Sriwijaya University, Indonesia \\ ${ }^{3}$ Department of Physiology, Faculty of Medicine, Sriwijaya University, Indonesia
}

Received date: December 24, 2019. Accepted date: February 3, 2020. Published date: February 20, 2020.

\section{KEYWORDS}

filter paper disc method; non-vegetarians taste sensitivity; vegans

\begin{abstract}
Introduction: Many studies have shown that nutritional deficiencies can affect taste sensitivity. One group at high risk of nutritional deficiencies is vegans. Objective: The aim of the present study was to investigate the differences in taste sensitivity between vegans and nonvegetarians in Palembang, Indonesia. Methods: This was an observational analytic study with a quasi-experimental approach. A total of 60 subjects aged 21-45 years were included in this study. The subjects were divided into two groups: vegans $(\mathrm{n}=30)$ and non-vegetarians $(\mathrm{n}=$ 30). Taste sensitivity was measured using the filter paper disc method. Five taste qualities (sweet, salt, sour, bitter, and umami) were tested using four different concentrations for each taste quality. The lowest concentrations identified correctly by the subjects were recorded as the taste sensitivity scores. The taste sensitivity scores were subsequently summed to form the taste scores. The data were analyzed using the Mann-Whitney $U$ test. Results: The mean values of the sweet, bitter, and umami taste sensitivity scores and the taste score in the vegan group were lower than those in the non-vegetarian group. The mean value of the salt taste sensitivity score in the vegan group was higher than that of the non-vegetarian group, while the mean value in the sour taste sensitivity score was the same for both groups. There were no significant differences in the sweet, salt, sour, bitter, and umami taste sensitivity scores and taste scores of the vegan and non-vegetarian groups ( $p>0.05)$. Conclusion: The vegans and non-vegetarians in Palembang in this study have differences in taste sensitivity, but these results are not significant.
\end{abstract}

\footnotetext{
${ }^{\circledR}$ Corresponding Author

E-mail address: shanty.c@fk.unsri.ac.id (Chairani S)
} 


\section{INTRODUCTION}

Taste sensitivity is the ability of an individual to recognize taste qualities at the minimum tastant concentrations. ${ }^{1}$ Taste qualities are differentiated into sweet, salty, sour, bitter, and umami. One of the organs that is important in the perception of taste is the tongue. Specifically, tastants that enter the oral cavity dissolve in saliva and then bind to the taste receptors on the taste buds of the tongue papillae. The result is a receptor potential that leads to the release of neurotransmitters. This stimulus is then forwarded to the brain where it is interpreted into the perception known as taste. ${ }^{2}$

The American Laryngological, Rhinological and Otological Society study reported that taste disturbance is prevalent in approximately one in 20 individuals. $^{3}$ Similarly, a decrease in taste sensitivity, known as hypogeusia, can be found in $5 \%$ of the population. ${ }^{4}$ Individuals with decreased taste sensitivity may change their dietary habits by consuming excessive amounts of tastants. ${ }^{5}$ Such disturbance-associated dietary alterations can lead to various diseases, including obesity and diabetes mellitus. ${ }^{6}$ Vitamins play an important role in maintaining the integrity of the oral mucosa, including the tongue papillae, and a deficiency in vitamin $B_{12}$ causes the tongue papillae to atrophy. It has also been observed that a deficiency in vitamins A and D could affect the functioning of the salivary glands, which can in turn lead to reduced salivary secretions. ${ }^{7}$ Reduced salivary secretions in the oral cavity can induce a decrease in taste sensitivity, as indicated by SatohKuriwada et al., who reported an association between hyposalivation and hypogeusia in the elderly. ${ }^{8}$

The component of saliva that plays an important role in the taste perception process is zinc ion. ${ }^{9}$ Zinc ion is a component of the protein carbonic anhydrase (CA-VI), which is closely related to growth and the development of taste buds. ${ }^{10}$ Many studies have reported that taste sensitivity decreases in individuals with zinc and CA-VI protein deficiencies. ${ }^{11,12}$ Other components of saliva that play an important role in the taste perception process are metabolic proteins such as leptin, glucagon-like peptide-1 (GLP-1), ghrelin, and peptide YY (PYY). ${ }^{13}$ Increased leptin and decreased GLP-1 concentrations have been shown to result in decreased sensitivity to sweet tastants, while increased GLP-1 leads to decreased sensitivity to umami tastants. ${ }^{13,14}$ Loper et al. showed that ghrelin reduced taste responsivity tosalty tastants, and PYY plays a role in the modulation of bitter tastes. ${ }^{14}$

Accordingly, it is evident that nutritional deficiencies can affect taste sensitivity. One group at high risk of nutritional deficiencies is vegans. Vegans are people who do not consume any animal products, including milk and eggs. ${ }^{15}$ This can lead to nutritional deficiencies, particularly due to the lack of animal proteins from milk and eggs. Schüpbach et al. reported that the intake of vitamins $\mathrm{A}, \mathrm{B}_{12}$, and $\mathrm{D}$ and the mineral zinc among vegans was lower than among non-vegetarians (people whose diet includes meat), with zinc showing the highest level of deficiency. ${ }^{16}$ Additionally, Belinova et al. reported that the healthy subjects who received vegan meals in their study had lower plasma concentrations of leptin, ghrelin, GLP-1, and PYY than the healthy subjects who consumed meat meals. ${ }^{17}$

It has been claimed that vegetarian diets could be beneficial in the prevention and treatment of certain diseases, such as hypertension, diabetes, and cancer. ${ }^{15}$ Interest in the adoption of vegetarian diets as part of a healthy lifestyle is therefore increasing. The number of vegetarians in Palembang, Indonesia, has grown rapidly to around 20,000 people in 2018 , of which the majority are vegans. ${ }^{18}$ Although it has been claimed that vegan diets are healthful, the nutritional deficiencies experienced by vegans may affect their health, including their taste sensitivity. The aim of the present study was therefore to investigate the differences in taste sensitivity between vegans and non-vegetarians in Palembang.

\section{MATERIALS AND METHODS}

\section{Subjects}

The present study was designed as an observational analytic study with a quasi-experimental approach. All the procedures were approved by the Health Research Review Committee of Mohammad Hoesin Central Hospital and the Faculty of Medicine, Sriwijaya University, Indonesia with Ethical Approval No.95/kepkrsmhfkunsri/2019). The study involved 60 healthy subjects between 21 and 45 years of age. The vegans $(n=30)$ comprised the congregation of the Maitreya Duta Palembang Monastery who had been following a vegan diet for at least a year, and the nonvegetarians $(n=30)$ were recruited from the SoeiGoeatKiong Temple. ${ }^{16}$ People with mucosal diseases of the tongue (e.g., stomatitis, candidiasis) and/or a history of systemic diseases, pregnant, breastfeeding, and menopausal women, smokers, people with food allergies or intolerances, and those who had had a drug-induced taste disorder within the previous three months were excluded from the study. ${ }^{19,20}$ The study procedure was explained to all the subjects, and their informed consent was obtained.

\section{Taste Sensitivity Test}

Taste sensitivity was measured using the filter paper disc (FPD) method. The test was conducted in the late 
morning due to the close correlation of the intensity of taste perception with diurnal quantitative salivary secretions. ${ }^{21}$ All the subjects were given clear instructions not to eat or drink anything except water and not to brush their teeth at least 1 hour before the test. Descriptions of the taste qualities (e.g., a sweet taste is like sugar, a salty taste is like salt, an umami taste is like monosodium glutamate) were only shared with the subjects immediately before the test. ${ }^{22}$ Five taste qualities were tested with four different concentrations for each taste quality (Table 1). ${ }^{23}$

A total of 22 FPDs, each $5 \mathrm{~mm}$ in diameter, were prepared for each subject. Twenty FPDs were used for the four different concentrations of sweet, salty, sour, bitter, and umami. Two blank FPDs were also included. During the test, the subjects were asked to rinse their mouths with distilled water and to wait approximately 1 minute before testing the next concentration. The FPDs were impregnated with the taste solution and then placed on the tongue approximately $2 \mathrm{~cm}$ from the tip of the tongue. ${ }^{23}$ The subjects were then asked to close their mouths and to choose one of six possible answers on a taste indicator chart (sweet, salty, sour, bitter, umami, and no taste). The procedure was done randomly, starting from the lowest concentration of each taste solution until the subjects identified each taste quality correctly. ${ }^{24}$ The lowest concentrations identified correctly by the subjects were recorded using a taste sensitivity score, which ranged from 0 to 4 . If the subjects did not perceive a concentration score of 1 , they received a score of $0 .^{23}$ Each subject's taste sensitivity score was subsequently summed to form an overall taste score. Overall taste score lower than 12 was considered as hypogeusia. ${ }^{25}$

\section{Statistical Analysis}

The taste sensitivity and taste scores were expressed as means. The normality of both scores was examined using the Shapiro-Wilk test and were found to be nonnormally distributed. The differences in taste sensitivity between the vegan and non-vegetarian groups were analyzed using the Mann-Whitney $U$ test. A $p$-valueless than 0.05 was considered statistically significant.

\section{RESULTS}

The characteristics of the vegans and nonvegetarians are presented in Table 2 . The mean values of the sweet, bitter, and umami taste sensitivity and taste scores were lower in the vegan group than in the nonvegetarian group. The mean value of the salty taste sensitivity scores in the vegan group was higher than in the non-vegetarian group, while the mean values of the sour taste sensitivity scores were the same in both groups. The $p$-values of the sweet, salty, sour, bitter, and umami taste sensitivity and taste scores were $0.75,0.62,1.00$, $0.20,0.54$, and 0.46 , respectively. The results showed that there were no significant differences in the sweet, salty, sour, bitter, and umami taste sensitivity and taste scores between the vegan and non-vegetarian groups ( $>0.05)$ (Table 3).

Table 1. The taste solution concentrations

\begin{tabular}{lccccc}
\hline & Taste & \multicolumn{5}{c}{ Concentration(g/ml) } \\
\cline { 3 - 6 } Tastant & \begin{tabular}{c} 
Quality \\
\cline { 3 - 5 }
\end{tabular} & 1 & 2 & 3 & 4 \\
\hline Sucrose & Sweet & 0.4 & 0.2 & 0.1 & 0.05 \\
$\begin{array}{l}\text { Sodium } \\
\text { chloride }\end{array}$ & Salty & 0.25 & 0.1 & 0.04 & 0.016 \\
$\begin{array}{l}\text { Citric } \\
\text { acid }\end{array}$ & Sour & 0.3 & 0.165 & 0.09 & 0.05 \\
$\begin{array}{l}\text { Quinine } \\
\text { hydro- } \\
\text { chloride }\end{array}$ & Bitter & 0.006 & 0.0024 & 0.0009 & 0.0004 \\
$\begin{array}{l}\text { Mono- } \\
\text { sodium } \\
\text { glutamate }\end{array}$ & Umami & 0.25 & 0.1 & 0.04 & 0.016 \\
\hline
\end{tabular}

Table 2. The characteristics of the study subjects

\begin{tabular}{lcc}
\hline Characteristics & $\begin{array}{c}\text { Vegans } \\
(\mathrm{n}=30)\end{array}$ & $\begin{array}{c}\text { Non- } \\
\text { vegetarians } \\
(\mathrm{n}=30)\end{array}$ \\
\hline Sex & 12 & 13 \\
Male & 18 & 17 \\
$\quad$ Female & 32.46 & 29.43 \\
Mean age (years) & 5.67 & - \\
Mean diet duration (years) & & \\
Mean taste sensitivity & 3.43 & 3.56 \\
scores of & 3.50 & 3.43 \\
$\quad$ Sweet & 3.80 & 3.80 \\
Salty & 3.56 & 3.80 \\
Sour & 3.16 & 3.33 \\
Bitter & & \\
Umami & 17.46 & 17.93 \\
Mean taste score & & \\
\hline
\end{tabular}

\section{DISCUSSION}

The present study hypothesized that vegans had a lower sensitivity to some tastes compared to nonvegetarians. A deficiency of vitamin $B_{12}$ in vegans can cause the tongue papillae to atrophy, which can lead to decreased taste sensitivity. ${ }^{7}$ Notably, Pontes et al. reported glossitis as an oral manifestation of vitamin $\mathrm{B}_{12}$ deficiency in vegans. ${ }^{26}$ In addition, Patil et al. showed 
Table 3. The taste sensitivity and taste scores

\begin{tabular}{|c|c|c|c|}
\hline \multirow{2}{*}{$\begin{array}{c}\text { Taste } \\
\text { quality }\end{array}$} & Vegans & $\begin{array}{c}\text { Non- } \\
\text { vegetarians }\end{array}$ & \multirow{2}{*}{$\begin{array}{c}\mathrm{p}- \\
\text { value }\end{array}$} \\
\hline & $\begin{array}{c}\text { Median } \\
(\text { Min-Max) }\end{array}$ & $\begin{array}{c}\text { Median } \\
(\text { Min-Max) }\end{array}$ & \\
\hline Sweet & $4.00(1-4)$ & $4.00(2-4)$ & 0.75 \\
\hline Salty & $4.00(1-4)$ & $4.00(2-4)$ & 0.62 \\
\hline Sour & $4.00(3-4)$ & $4.00(3-4)$ & 1.00 \\
\hline Bitter & $4.00(1-4)$ & $4.00(3-4)$ & 0.20 \\
\hline Umami & $3.00(1-4)$ & $3.50(2-4)$ & 0.54 \\
\hline $\begin{array}{l}\text { Taste } \\
\text { score }\end{array}$ & $18.00(14-20)$ & $18.00(15-20)$ & 0.46 \\
\hline
\end{tabular}

that candidal prevalence was higher in vegetarians than in non-vegetarians. ${ }^{27}$ Decreased taste sensitivity is also associated with a lower zinc intake in vegans. ${ }^{16}$ All these findings may contribute to the decrease in taste sensitivity experienced by vegans.

In this study, the vegan group had lower sweet, bitter, and umami taste sensitivity scores than the nonvegetarian group. This result could have been influenced by the deficiency in certain metabolic proteins, such as GLP-1 and PYY, among the vegans. ${ }^{13,14}$ Notwithstanding, the salty taste sensitivity score was higher among the vegans than among the non-vegetarians. This result supports the study by Loper et al., which found that a reduction in ghrelin increases the salty taste response. ${ }^{14}$

The sour taste sensitivity scores among the vegans and non-vegetarians in our study were the same, which is similar to the results reported by Overberg et al., who found no difference in the sour taste sensitivity scores among obese and non-obese subjects. ${ }^{22}$ Similarly, Saluja et al. noted the same sour taste sensitivity scores for the menstruation, pregnancy, and menopause groups in their study. ${ }^{21}$ These results indicate that not many factors can alter taste sensitivity to the sour taste.

The umami taste sensitivity score was the lowest score in both groups in this study. This can be explained by the confusion experienced by many of the subjects with regard to the umami taste. ${ }^{25}$ The possibility of an umami taste being confused with a salty taste was reported by Mueler et al., who found that $28 \%$ of the FPDs for all concentrations of the umami taste in their study were identified as the salty taste. ${ }^{24}$ In this study, a taste sensitivity score was only recorded if the subjects identified the taste solutions correctly. Further, it should be noted that, if the subject misidentified the taste qualities or the taste qualities were not recognized by the subject, then a score of 0 was allocated.
In this study, only two subjects in the vegan group had taste sensitivity scores lower than 2, each in sweet and salty taste. Meanwhile, all the subjects in both groups had bitter taste sensitivity scores higher than 1, as well as taste scores higher than 14. A previous study categorized subjects as normal (normogeusia) when their sweet, salty, and sour taste sensitivity scores were higher than or equal to 2 , their bitter taste sensitivity scores were higher than or equal to 1 , and their taste scores were higher than or equal to $9 .{ }^{23}$ If the results were lower than the normal values, then the subjects were categorized as hypogeusiac. Based on these parameters, this study found that all the non-vegetarian subjects were normal (normogeusia), while two of the vegan subjects were categorized as hypogeusiac, both for the sweet and salty tastes.

The recruitment of the vegan subjects was based on a questionnaire in this study. Future research should include more subjects, and the recruitment of vegans should involve the use of a food-frequency questionnaire (FFQ). For example, Schmidt et al. used an FFQ with 130 questions regarding food and beverage types, and 113 of these questions were relevant to vegans/vegetarians. ${ }^{28}$

In this study, the differences in taste sensitivity between the vegan and non-vegetarian groups were not significant. Several factors may have influenced this result. With regard to vegans, the consumption of supplements and fortified products can reduce the risk of nutritional deficiencies; however, this was not explored in this study. ${ }^{29}$ Another relevant factor was the concentrations used in this study.

The lowest concentration in this study was higher than that of a study by Constanzo, et al. in which the whole mouth method was used. ${ }^{5}$ In that study, most of the subjects were able to recognize the tastes in the lowest concentrations of the taste solutions. The lowest concentrations in this study were $0.31 \mathrm{mg} / \mathrm{ml}$ to 59.75 $\mathrm{mg} / \mathrm{ml}$ higher than those in the Constanzo et al. study. Further studies using lower concentrations are therefore needed.

\section{CONCLUSION}

The differences in sweet, salty, sour, bitter, and umami taste sensitivity were found between vegans and non-vegetarians in Palembang. However, these differences are not significant. Further studies with better research methods are expected to confirm this results.

\section{CONFLICT OF INTEREST}

The authors declare that they have no conflict of interest. 


\section{REFFERENCES}

1. Bertoli S, Laureati M, Battezzati A, Valentina B, Cereda E, Spadafranca A, et al. Taste sensitivity, nutritional status and metabolic syndrome: Implication in weight loss dietary interventions. World J Diabetes. 2014;5(5):717-23.

2. Tortora GJ, Derrickson B. Principles of anatomy and physiology. 14 ${ }^{\text {th }}$ Ed. United Kingdom: Willey; 2014. p.576-8, p.895-6.

3. Bhattacharyya N, Kepnes LJ. Contemporary assessment of the prevalence of smell and taste problems in adults. The Laryngoscop. 2014;125(5):1102-6.

4. Ekback G, Ordell S. Self-perceived taste disturbance: a 20-year prospective study of a Swedish 1942 birth cohort. Gerodontology. 2017;34:180-186.

5. Costanzo A, Orellana L, Nowson C, Duesing K, Keast R. Fat taste sensitivity is associated with shortterm and habitual fat intake. Nutrients. 2017;9(781): $1-12$.

6. Su N, Ching V, Grushka M. Taste disorders: a review. J Can Dent Assoc. 2013; 79:d86.

7. Touger-Decker R, Mobley C, Epstein JB. Nutrition and oral medicine. $2^{\text {nd }}$ ed. USA: Humana Press; 2014. p. 117-8.

8. Satoh-Kuriwada S, Noriaki S, Misako K, Hisayuki U, Naoto K, Takashi S. Hyposalivation strongly influences hypogeusia in the elderly. Japan: J Health Sci. 2009;55(5):689-98.

9. Fábián TK, Beck A, Fejérdy P, Hermann P, Fábián G. Molecular mechanisms of taste recognition: considerations about the role of saliva. Int $\mathrm{J}$ Mol Sci.2015; 16:5945-74.

10. Ambaldhage VK, Puttabuddi JH, Nunsavath PN, Tummuru YR. Taste disorders: A review . J Indian Acad Oral Med Radiol. 2014;26:69-76.

11. Aliani M, Udenigwe CC, Girgih AT, Pownall TL, Bugera JL, Eskin MNA. Zinc deficiency and taste perception in the elderly. Crit Rev Food Sci Nutr. 2013; 53:245-50.

12. Okayama T, Watanabe H. Association between taste perception, nutrient intake, and mental health in young Japanese women. Nutr Res Pract. 2019;13(1): 41-6.

13. Yoshida R. Hormones and bioactive substances that affect peripheral taste sensitivity. JOB. 2012;54: 6772.

14. Loper HB, Sala LM, Dotson C, Steinle N. Taste perception, associated hormonal modulation, and nutrient intake. Nutr Rev. 2015; 73(2):83-91.

15. Craig WJ. Position of the American dietetic association: vegetarian diets. J Am Diet Assoc. 2009;109(7):1266-82.

16. Schüpbach R, Wegmüller R, Berguerand C, Bui M,
Herter-Aeberli. Micronutrient status and intake in omnivores, vegetarians and vegans in Switzerland. Eur J Nutr. 2017;56: 283-93.

17. Belinova L, Kahleova H, Malinska H, Topolcan O, Vrzalova J, Oliyarnyk O, et al. Differential acute postprandial effects of processed meat and isocaloric vegan meals on the gastrointestinal hormone response in subjects suffering from type 2 diabetes and healthy controls: a randomized crossover study. PLoS One. 2014;9(9):1-10.

18. Putri K, Sriati, Yunita. The consumer perceptions and organizational strategy of Indonesia Vegetarian Society (IVS) in increasing to consumption vegetable cuisine in Palembang city. IOSR-JBM. 2018;20(8):62-73.

19. Chairani S, Putri A, Rusdiana S. Perbedaan sensitivitas pengecapan pada masa ovulasi, menstruasi, dan pasca menopause. Dentika Dental J 2013;17(3):207-11.

20. Schiffman SS. Influence of medications on taste and smell. World J Otorhinolaryngol Head Neck Surg. 2018;4(1):84-91.

21. Saluja P, Shetty V, Dave A, Arora M, Hans V, Madan A. Comparative evaluation of the effect of menstruation, pregnancy and menopause on salivary flow rate, $\mathrm{pH}$ and gustatory function. J Clin Diagn Res. 2014; 8(10):81-5.

22. Overberg J, Hummel T, Krude H, Wiegand S. Differences in taste sensitivity between obese and non-obese children and adolescents. Arch Dis Child. 2012;97:1048-52.

23. Mueller C, Kallert S, Renner B. Quantitative assessment of gustatory function in a clinical context using impregnated taste strips. Rhinology. 2003;41:2-6.

24. Mueller CA, Pintscher K, Renner B. Clinical test of gustatory function including umami taste. Annals of Otology, Rhinology \& Laryngology. 2011; 120(6):358-62.

25. Hwang CS, Kim JW, Sharhan SSA, Kim JW, Cho H, Yoon J, et al. Development of a gustatory function test for clinical application in Korean subjects. Yonsei Med J. 2018;59(2):325-30.

26. Pontes HA, Neto NC, Ferreira KB, Fonseca FP, Vallinoto GM, Pontes FSC, et al. Oral manifestations of vitamin $\mathrm{B}_{12}$ deficiency: A case report. J Can Dent Assoc. 2009;75(7):533-7.

27. Patil S, Rao RS, Raj AT, Sanketh DS, Sarode S, Sarode G. Oral candida carriage in subjects with pure vegetarian and mixed dietary habits. J Clin Diagn Res. 2017;11(7):22-4.

28. Schmidt JA, Rinaldi S, Ferrari P, Carayol M, Achaintre D, Scalbert A. Metabolic profiles of male meat eaters, fish eaters, vegetarians, and vegans from the EPIC-Oxford cohort. Am J Clin Nutr. 2015;102:1518-26. 
29. Kahleova H, Levin S, Barnard L. Cardio-metabolic benefits of plant-based diets. Nutrients.

2017;9(848):1-13. 